The Effects of a Green Nudge on Municipal Solid Waste: Evidence from a Clear Bag Policy

\author{
by \\ Mevlude Akbulut Yuksel \\ Dalhousie University \\ and \\ Catherine Boulatoff \\ Dalhousie University
}

Working Paper No. 2020-06

November 3o, 2020

DEPARTMENT OF ECONOMICS

DALHOUSIE UNIVERSITY

6214 University

Avenue PO Box 15000

Halifax, Nova Scotia, CANADA

$\mathrm{B}_{3} \mathrm{H} 4 \mathrm{R} 2$ 


\title{
The Effects of a Green Nudge on Municipal Solid Waste: Evidence from a Clear Bag Policy
}

\author{
Mevlude Akbulut Yuksel and Catherine Boulatoff*
}

\begin{abstract}
We explore the power of behavioral economic insights to influence the level of households' recycling and Municipal Solid Waste (MSW) by examining the effectiveness of a green nudge, the adoption of a Clear Bag Policy that was implemented in 2015 in a mid-size urban municipality in Canada. Using a Regression Discontinuity (RD) Design on universe administrative data, our analysis shows that this green nudge promoted recycling, and reduced both refuse and total MSW. While recycling increased by 15 percent, total MSW decreased by 27 percent overall between August 2015 and July 2017. Our results also demonstrate heterogeneity in response to a Clear Bag Policy across neighborhoods with varying socioeconomic indicators. Our findings suggest that green nudges can serve as effective policy instruments in devising future environment policies.
\end{abstract}

Keywords: Environmental policy, green nudge, Municipal Solid waste (MSW), Regression discontinuity design, ArcGIS

JEL Classification: D12, D91, H23.

*Akbulut-Yuksel, Dalhousie University, Department of Economics, Halifax, Canada, email:mevlude@dal.ca; Boulatoff: Dalhousie University, Department of Economics, Halifax, Canada, email:Boulatoff@dal.ca. We thank Laurie Lewis and Clayton Pemberton, HRM Solid Waste Resources, Halifax, Canada, for their help in providing the data used in this study. We also thank Jennifer Strang, GIS analyst at Dalhousie University, for her help in combining census data with waste data, Paola Beneras for excellent research assistance, Yulia Kotlyarova, Jonaiada Milla, Dozie Okoye, Casey Warman, Mutlu Yuksel, as well as seminar participants at Dalhousie University, the 2018 Canadian Economic Association (CEA), and at the 6th World Congress of Environmental and Resource Economists (WCERE), 2018, for their helpful comments, and anonymous referees who provided feedback which improved the paper. This work was supported by the Social Sciences and Humanities Research Council (SSHRC). 


\section{Introduction}

The astounding growth in Municipal Solid Waste (MSW) generation over the last three decades continues to inflict substantial management costs and a heavy environmental burden on citizens and local governments alike. Higher income and wealth, with their resulting increase in the consumption of goods and services, higher urbanization rates, and changes in production methods leading to a greater use of packaging materials, are deemed to be the chief factors (D'Amato et al., 2016). Excessive amounts of waste or garbage are notoriously found in oceans and in the food chain and are increasingly being traced back into our food. The over consumption of resources and the creation of plastics has become one of today's most pressing environmental challenges (Hoomweg and Bhada-Tata, 2012; Barr et al., 2001, Zacho and Mosgaard, 2016). Until recently, China was the dominant market for recycled plastic, and its announcement in 2018 that it would no longer accept recyclables (i.e., plastic, paper, and textile) has intensified many countries' already pressing MSW problem. Alternatives to shipping plastics overseas are limited: incineration is typically frowned upon because of the air pollution it produces, and many places are already facing space constraints in landfills.

The bulk of waste management policies in many countries have relied on "end of pipe" approaches. The objective was to achieve greater levels of recycling or to improve waste disposal management (Cecere et al., 2014, Kinnaman et al., 2014, Zacho and Mosgaard, 2016). Mandatory and voluntary recycling programs as well as price incentive and non-price incentive programs were among the different types of policies implemented (Dahlen and Lagerkvist, 2010). In addition to environmental policies merely motivated by changing economic incentives, policy makers are increasingly incorporating psycho-social content of preferences including extrinsic motivations such as social norms and intrinsic motivations such as altruistic preferences in the design of the environment policies, particularly to encourage waste prevention 1 As importantly, these new policies aim at utilizing the power of social influence and moral tax in their design ${ }^{2}$ Because people typically care

\footnotetext{
${ }^{1}$ More specifically, the literature on psycho-social content of preferences postulates that an individual's preferences are also constructed in a social context (Ariely et al. 2006 Kahneman, 2011 Cecere et al. 2014) and by giving information about norms. A detailed description of the moral nudge concept can be found in (Carlsson and Johansson-Stenman, 2019).

${ }^{2}$ The term of moral tax was used in Brent et al. (2016) which investigated the impact of normative pressure to promote water conservation in Reno, Nevada. One of the underlying behavioral mechanisms often cited to explain how consumers respond to normative appeals (Ferraro and Price, 2013, cited in Brent et al. 2016, p2) is moral motivation, the "social norm message that raises the psychic cost of consumption for the consumer, and [explains how,] in response the consumer self-imposes a moral
} 
about their self-image and often follow the crowd, perceptions of what other people do - obtained either directly or indirectly, through information given by a third party - have a powerful influence on agents' behaviors (Nolan et al., 2008; in Schubert, 2017, p.332).

Informed by insights in behavioral economics, "green nudges", a concept developed by Thaler and Sunstein (2008), are also being used increasingly in environmental policy to "gently push individuals in the right direction" (Alpizar and Gsottbauer, 2015, Schubert, 2017; Carlsson et al., 2019). One type of effective green nudge is making the green option the default option $?^{3}$ For example, in 2010, the local government of Fort Collins, Ohio, implemented a policy which switched the size of the garbage bins: the recycling went into a large 90-gallon container, while the refuse went into a smaller 35-gallon container 4 As a result, households increased their recycling efforts, showing that people tend to recycle as much as they are given space to do so.

To date, however, green nudges applied to MSW remain rare (Carlsson et al., 2019). In this paper, we attempt to fill the void in the literature by examining the causal effects of a green nudge, the mandatory use of clear plastic bags, on recycling, waste generation and prevention behaviors of households. To the best of our knowledge, this is one of the first papers that quantifies the effectiveness of a moral green nudge policy in MSW. The "Clear Bag Policy" has been instituted by the Regional Municipality Solid Waste Resources Department in the summer of 2015 in a medium size city in Canada with hopes of nudging households towards more responsible sorting and potentially reducing waste generation (Pemberton, 2018). The policy was universally implemented in all garbage collection areas and the municipality is the sole garbage collector in our setting; both of which further speak to it being a top down policy. Under the new garbage collection policy, households were mandated to replace the black garbage bags used for the disposal of the refuse with the clear, transparent bags while one dark bag was permitted for privacy. This new garbage

tax, reducing consumption." Similarly, Allcott and Kessler (2019) use the term of moral tax when discussing the measurement of moral utility, inquiring if "social comparisons [are] moral taxes on "bad behavior." In their paper, Allcott and Rogers (2014) further analyzed the impact of the social comparison-based home energy reports mailed to consumers. They find that at first, it had a strong impact on consumers' energy consumption, effect that remains somewhat persistent when these mailings were discontinued (Allcott and Rogers 2014).

${ }^{3}$ Even though, the above definition is generally used in the literature, the idea of a minimal cost being imposed on individuals that is associated with the concept of nudge is sometimes/often blurred. Hausman and Welch (2010) for instance note how even Thaler and Sunstein's own example of the requirement that firms publish "Toxic Release Inventories" may be less a nudge than a prescription. Similarly, asking consumers to pay a 5 cents for plastic bags also counts as a nudge (Hansen, 2016) when some could argue that it refers more to a prescription.

${ }^{4}$ The bins were provided by the municipality without charge. In addition, in case of opting out of the policy, residents typically can decide to purchase their own garbage bins, or, alternatively, bring their wastes to the landfill facility directly (http://nudges.org/2010/11/28/recycling-bin-choice-architecture); thus effectively making this policy a green nudge. 
collection policy can be classified as a moral green nudge since its design incorporated the various aspects of nudges we described earlier. Policies such as the Clear Bag policy we study in our paper cost relatively little to administer and implement by local governments, and have the potential to alleviate some of the MSW challenges. Therefore, it is of policy interest to credibly quantify the effectiveness of green nudge policies increasingly being implemented in environmental policy on promoting recycling, better sorting, and ultimately reducing total waste.

Further, in our paper we provide suggestive evidence on the potential heterogeneous effects of the Clear Bag Policy across garbage collection areas with various socio-economic indicators. Previous studies have shown that economic instruments such as income, education, and social influence are key factors explaining the patterns in selective sorting behavior (Meyer, 2015, Kirakozian, 2016), while the prevention of waste does not seem to be motivated by social pressure or norms, or by economic incentives (Barr et al. 2001). Our analysis indeed demonstrates a significant heterogeneity in response to the policy change by education and income.

Essential to the purpose of this paper, the sharp and unexpected policy change in the garbage collection rules instituted in the summer of 2015 provides us with a unique quasi-experimental setting to causally estimate the effects of green nudge waste management policies on households' recycling and waste generation behaviors. More specifically, we exploit the discrete and abrupt change in the waste management rules engendered by the Clear Bag Policy to implement a highly credible RD design. This design exploits the differences in total waste, recycling, and refuse amounts and rates in the weeks preceding and following August 1st, 2015, the date the policy was launched.

We conduct our analysis using administrative municipal data on daily solid waste, where every weekday corresponds to a garbage collection area. Our data covers the entire population we study and provides detailed daily information on the amount of refuse, recycling, organics and total solid waste spanning several years before and after the implementation of the Clear Bag Policy. In this study, we focus on the downtown core and its five collection areas, each corresponding to a given day in the week. These areas were determined to allow for about the same number of trucks, staff and completion times on any given day (Pemberton, 2018).

Our novel administrative data offers several advantages over the previous research on the waste 
management, which utilize survey data. First, in contrast to previous studies 5 these data cover all the available information on household solid waste, thereby, we have information on the entire population. Since the municipality is the sole collector of garbage and because the policy was applied to all dwellings in the community (except large apartment complexes), our analysis effectively addresses any potential selection bias in participation to the policy or sorting around the announcement of the policy. Second, as our data represent daily records on solid waste, it allows us to estimate the effects of the green nudge policy more precisely, compared to previous research, which mainly utilize monthly or annual survey waste data. Third, having access to daily data allows us to identify the effects of the policy change within narrow bandwidths spanning several months at the maximum; thereby significantly mitigating the possibility of the potential confounders and other policy changes which could have risen in the analysis using the monthly or annual data. Further, we are able to observe both the immediate and medium-run effects of the Clear Bag Policy since our data spans several years before and after the policy change. This could potentially inform and aid policy makers in their design of the new environmental policies.

Using RD design on this universe administrative data, our analysis shows that the Clear Bag Policy has been effective in increasing recycling and reducing both refuse and overall MSW. More specifically, we find in our RD robust specification controlling for bias and variance and garbage collection area dummies that the Clear Bag Policy led to a 27 percent reduction in overall MSW, while increasing recycling by 15 percent compared to the pre-policy period. Our results also point to a substitution between refuse and recycling, suggesting households improved effort in more responsible recycling after the policy. We further find suggestive evidence that areas with lower average income and educational attainment exhibit more significant improvements in their waste management and generation, thereby demonstrating that green nudges could also be effective in alleviating differences in waste management across socioeconomic status. An increasing diversion of the redeemable items, clothing and small appliances from landfill and the growing use of the commercial garbage for fee are potential mediators explaining our findings. Our results are robust to a variety of alternative RD specifications with different data-driven bandwidth selection procedures, equal and different bandwidths in each side of the cut-off, a different degree of polynomials in

\footnotetext{
${ }^{5}$ See, Allcott and Kessler (2019), Alpizar and Gsottbauer (2015), Bernstad et al (2012), Cox et al (2010), Hoomweg and Bhada-Tata (2012).
} 
running variable, non-parametric kernel estimations and a battery of different placebo cut-offs.

The remainder of the paper is organized as follows: Section 2 provides a brief overview of Halifax Regional Municipality, some background on waste management policies and a description of the Clear Bag Policy instituted in August 2015; Section 3 describes our data; Section 4 discusses the identification strategy; Section 5 presents the main results, extensions and robustness checks; Section 6 includes the discussion of the results and Section 7 concludes.

\section{Background on Clear Bag Policy}

Halifax ${ }^{6}$ is the capital of Nova Scotia, an Eastern province of Canada. The regional municipality comprised over 361,600 inhabitants as of December 2017 (Statistics Canada, 2018), representing approximately $44 \%$ of the total population of Nova Scotia. Halifax is a major economic center in the Atlantic Provinces, with a large concentration of government services and private sector companies 7 The median family income in 2015 was $\$ 95,250$, which is higher than the Canadian national family median income $(\$ 88,610)$ that same year (Statistics Canada, 2017). The unemployment rate was $6.9 \%$ in December 2017. The average number of persons per census family in 2011 was 2.8 , and the average number of children living at home was one. Ninety two percent (92\%) of individuals aged 25 to 64 years had at least a college, CEGEP or other non-university certificate or diploma (Statistics Canada, 2011).

In Canada, individual municipalities are responsible for their own waste management programs, and often choose land filling. However, waste management programs are increasingly costly and often generate fierce opposition (see also the "not in my backyard", or NIMBY problem). In fact, creating landfills for disposal of garbage seems to have reached its limit in Canada since the early 2000s (Babooram and Wang, 2013). In Halifax, the Otter Lake landfill, commissioned in 1998, has been running since 1999. Within this exclusive landfill for HRM, recyclable resources must be

\footnotetext{
${ }^{6}$ It is legally known as Halifax Regional Municipality (HRM). The regional municipality consists of four former municipalities that were combined in 1996: Halifax, Dartmouth, Bedford, and the Municipality of Halifax County. The former City of Halifax is on a geographic region known as the Halifax peninsula. In this paper, "HRM" and "Halifax", unless otherwise noted, are used interchangeably.

${ }^{7}$ The largest employment sectors in Halifax include trade (36,400 jobs), health care and social assistance (31,800 jobs), professionals, scientific and technical services (19,000 jobs), educational services (17,400 jobs), and public administration (15,800 jobs) (Halifax Regional Municipality, 2016).
} 
recovered, organics must be composted, and hazardous waste must be kept at bay (Nova Scotia Environment, 1995).

There are eight collection zones in HRM, each of which is contracted to one collection company. In our study we focus on Zone 1, which is the urban core concentration of the former City of Halifax boundaries. Zone 1 includes a large area beyond the Halifax peninsula and is home to almost 127,000 people. It is divided into five garbage collection areas, which are named for the day on which collection occurs (from "Monday" to "Friday"). The boundaries defining collection days have existed since the 1970s. Each collection day is delineated so as to be serviced by the same number of trucks, staff and in similar completion times compared to the other areas (Pemberton, 2018). The collection companies generally submit two or three small change requests every five years; usually because one or two collection days have experienced growth in the number of units serviced but these changes can affect all five days as boundaries change (Pemberton, 2018$)$. No such change occurred in our period of interest.

The "South End" is located near downtown toward the south end part of the peninsula ("Monday area"). It is an affluent area that hosts many universities and hospitals as well as shopping areas, and is just a short commute to, if not within walking distance of, the downtown business core. The North End of Halifax ("Tuesday area") is predominately comprised of smaller to medium-sized homes and remains in close proximity to downtown Halifax. With peninsula real estate generally commanding a premium, many find more affordable opportunities in the North End. The West End of Halifax ("Wednesday area") is an upper-middle-class area, close to shopping centers and the downtown core, while also being close to the mainland and to highway access to outside the city. Both the Clayton Park and Spryfield areas - Thursday and Friday areas, respectively - are situated further away from downtown, and as such real estate is typically valued at a lower price.

In HRM, households are required to sort waste in four ways. Recyclable containers (plastics, glass, and aluminum) are to be put in a transparent "blue bag"; paper and cardboard 8 are to be put in a separate bag; organic food waste goes in the green bin provided by the city. The remaining waste (refuse) goes into garbage bags. Households are allowed up to six bags of refuse every other week.9 Recyclable materials are collected each week, while garbage and organic waste are each

\footnotetext{
${ }^{8}$ Cardboard can also be flattened and bundled separately.

${ }^{9}$ The full details of residential garbage collection rules can be found at http://www.halifax.ca/recycle/garbage.php (ac-
} 
collected every other week on opposite weeks (except in the summer months, when organic waste is collected on a weekly basis).

In its search for effective ways of reducing the garbage from municipal solid waste that will go to landfill, starting in 1995 the province of Nova Scotia implemented a Resource Management Strategy for Solid Waste, with the aim of $50 \%$ solid waste diversion from landfill by 2000 (Nova Scotia Environment, 2014). HRM's goal was to divert $60 \%$ of its waste. In addition to maintaining this target through traditional waste diversion practices, HRM also explored various new strategies, the latest of which was the Clear Bag Policy, implemented on August 1, 2015 via by-law No. S-609. The Clear Bag Policy was a top down program designed by the administrative unit of the Halifax Regional Municipality Solid Waste Resources Department with the intentions of incorporating the behavioral insights in MSW collection in HRM ((Pemberton, 2018) $)$. This intention was also communicated to the public via newspaper and other means of communication (for instance, see CBC, July 23, 2015). The policy was universally implemented in all garbage collection areas; which further speaks to it being a top down policy 10 The launch and the implementation of the policy were exogenous to household behavior, thereby providing us a novel opportunity to study the effects of this green moral nudge employing a quasi-experiment estimation framework such as highly credible regression discontinuity design we discuss next.

More specifically, the mandated Clear Bag Policy still allows households to have the same number of waste bags at the curb (six every other week), but all waste destined for landfill must be disposed of in a clear bag (except for one dark bag that is permitted for privacy). This allows waste collectors to screen bags and refuse them if they are deemed to include materials that should be diverted from the landfill, such as recyclables, food waste, and hazardous waste. Clear bags also make it very apparent to everyone, neighbors and passersby alike, whether people recycle or what they waste. Such policy is a good example of the growing policies that rely on moral nudges, which, in comparison to a cognitive nudge, draws on people's social preferences, their desire for status, to cessed March 17, 2017).

${ }^{10}$ Moreover, none of the garbage collection areas or other stakeholders were involved in the design of the program Pemberton, 2018). Indeed, given the proximity of the garbage collection areas to each other and their size, there is no justifiable reason to expect that a certain garbage collection area collectively requesting change but not others. In addition, there was no public outcry or public push towards changing garbage collection rules prior or at the launch of the policy as can be attested from the local newspapers and other venues. 
follow norms and to have a positive self-image" (Carlsson et al., 2018, p.6) ${ }^{11}$

\section{$3 \quad$ Data and Descriptive Statistics}

Our empirical analysis utilizes an administrative data on MSW on the entire population provided by the Halifax Solid Waste Resources Department. The data span the period from January 6, 2014, to July 28, 2017, and correspond to 930 garbage days. The waste data include the weight (in tonnes) of the weekly recycling and the bi-weekly garbage generated by households by garbage type within the five collection areas but exclude those for condominiums or apartments with more than six units. We matched the frequencies for the recycling and garbage data by dividing the bi-weekly waste and organics (except in the summer months) data by two, thus making all data weekly measures. The weight of the recycling waste was then divided by the total weight of all recycling and garbage (including organics) to obtain the recycling rate. Since each collection area corresponds to one day of the week, as a result, we have daily data.

Data on demographic characteristics, such as income, education level, and employment rate, were obtained from the 2011 Canadian Census. Dissemination areas (DAs) are the smallest geographic unit for census data, usually containing 400-700 persons (Statistics Canada, 2016). We linked the waste and census data using ArcMap, the main part of the geographic information system software ArcGIS, which can use maps to view and manage geospatial data. This allowed us to calculate the average income, average education level and average employment rate for each of the five solid waste collection areas. We utilized these census data to tackle a potential heterogeneity across garbage collection areas in response to the Clear Bag Policy.

The income data indicate the average income per person aged 15 and over. Education level is represented by the percentage of people who have a post-secondary certification, diploma or degree. Employment represents the percentage of individuals employed. We calculated averages for every demographic variable within each waste collection area. For example, the average incomes for different collection areas were calculated as follows: each municipal solid waste (MSW) collection

\footnotetext{
${ }^{11}$ Green nudges can be classified in different groups. While a "cognitive" green nudge would "aim to correct bounded rationality, inattention or self-control problems and thus to steer behavior mainly by making it easier to "do the right thing" (Hansen 2016. Carlsson et al. 2019), a "moral" [green] nudge "draws on people's social preferences, their desire for status, to follow norms or to have a positive self-image" (Carlsson et al., 2019).
} 
area contains several DAs, which each has the information regarding the average income within that DA. Empirically, the new average income based on collection areas was calculated by taking the average of the income for those dissemination areas that overlapped in one collection area. This can be seen in Figure 1, which shows how the dissemination areas of HRM overlap the waste collection areas, where the pink to red areas are HRM areas and the DAs are delimited by grey lines.

Table 1 presents descriptive statistics for recycling and solid waste as well as the recycling and solid waste rates, before and after the policy change respectively. As can be seen in the table, the recycling rate increases significantly (at the 1\% level) overall after the Clear Bag Policy, from 17.4\% before the policy implementation to $20.2 \%$ afterward. As expected, this increase in recycling also transpires in the overall decline in refuse rate, from $49.9 \%$ before the policy was implemented to $41.5 \%$ afterward. Yet, interestingly, the total MSW (refuse + recycling + organics) also seems to have decreased significantly between 2014 and 2017. The average weight of total MSW amounted to 97.252 tonnes per week before the Clear Bag Policy but dropped to 88.947 tonnes afterward (a significant difference at the 1\% level). This represents $195 \mathrm{kgs}$ of MSW per person per year before the policy was implemented, and $179 \mathrm{kgs}$ per year afterward. ${ }^{12}$ These raw differences are reassuring; the green nudge seems to lead effectively to an increase in recycling (reuse), paired with an overall reduction in waste (reduce) 13

Table 2 describes our demographic variables for each garbage collection area, based on the census data outlined above. Summary statistics point out to observable differences in socioeconomic indicators across garbage collection areas. Garbage collection area 1 (i.e., South End) has a population with a higher education level overall, with about $61 \%$ of persons holding a post-secondary certification, diploma, or degree (compared to $50 \%$ or under in other areas). This area also exhibits a higher employment level (71\% compared to 49-55\% in other areas), and a greater annual income, with almost $\$ 50,000$ per person on average, compared to $\$ 35,000$ - $\$ 40,000$ in other areas. These unadjusted descriptive statistics presented in Table 1 and Table 2 are suggestive, but a more in-depth econometric analysis are needed to credibly quantify whether the changes in recycling,

\footnotetext{
${ }^{12}$ These figures were calculated by multiplying total MSW per week (97,252 tonnes before and 88,947 tonnes after the policy) by the number of weeks in a year $(52)$, and dividing it by the average population $(25,903)$.

${ }^{13}$ We note that the magnitude of illegal dumping in Halifax did not appear to change during this time period. Therefore, it is not likely that the observed reduction in MSW is an merely artefact of illegal off-site dumping.
} 
refuse, and total MSW that are observed hereby can indeed be attributed to the Clear Bag Policy.

In addition to quantifying overall effect of the Clear Bag policy on waste management, we are also interested in assessing whether households' socioeconomic background, which we proxy by the census data led to differential responses to the green nudge policy. Appendix Tables 1A-1D include the descriptive statistics for the amount of total solid waste, refuse, recycling and organics before and after the policy change by garbage collection area, respectively. We focus on the total solid waste across garbage collection areas in Appendix Table 1A. Looking first at the period before the policy, we see that the total MSW varied somewhat between areas, between nearly 86 tonnes per week (North End) and 107 tonnes per week (Spryfield). However, these initial differences should be treated with caution. First, as was indicated earlier, these areas were defined originally so as to require constant numbers of trucks and staff, and similar completion times. Second, these areas represent different population levels, and these population numbers are somewhat imprecise; they may include residents living in apartment buildings with more than six units, while no MSW data are available for these units. Some areas, such as Clayton Park, North End and West End, contain more multi-unit buildings than others, such as the South End. However, we later control for garbage area fixed effects in our global regressions and RD specification to account for differences across areas (in global regressions) and increase efficiency (in RD analysis).

More interestingly, Appendix Tables 1A-1D point out how the policy impacts each garbage collection area using unadjusted raw data. Column (4) of each table tests for the change in garbage generation (i.e., total MSW, refuse, recycling, and organics) after the policy and presents the amount of change as a result of policy and the associated standard errors. Overall, we observe a significant shift in waste after the implementation of Clear Bag Policy across all collection areas, except for the South End. All areas exhibit significant decreases in the overall MSW being generated after the policy change, with the greatest decrease being experienced by Spryfield with almost 12 tonnes less per week. The amount of refuse generated has substantially declined after the green nudge policy, between 8 tonnes per week in South End and 14 tonnes per week in Spryfield (Appendix Table 1B). Unadjusted descriptive statistics also reveal that recycling increased significantly across all collection areas except for the North End (as shown in Appendix Table 1C), with the largest increase being in Spryfield $(+2$ tonnes per week) and the smallest in the North End. 
Finally, it seems that organic waste increased in the South End (more affluent area of the city) by 6 tonnes per week after the policy change and this change is statistically significant, while it remains somewhat unchanged in other areas (see Appendix Table 1D). Taken together, these results point out to a heterogeneity in response elasticity to the Clear Bag Policy across areas. We tackle this suggestive heterogeneity in more detail in the estimation results section.

\section{Identification Strategy}

As detailed in the background section, the Clear Bag policy abruptly and unexpectedly changed the garbage collection rules independent of ex-ante household behavior; thereby providing a unique quasi-experimental setting to causally estimate the effects of the non-price waste management policies such as green nudge on households' recycling and waste generation behaviors. In this pursuit, we explore the discrete and abrupt change facilitated by this new waste management policy and implement a RD Design in our analysis. This design exploits the differences in total waste, recycling, and refuse amounts and rates in the weeks preceding and following August 1st, 2015, the date at which the policy was launched.

We begin by exploring the discontinuity at the week and year, and present the reduced form estimates from a sharp RD design. More specifically, we estimate the following basic RD specification:

$$
\begin{aligned}
& Y_{i}=\alpha+\beta t_{i}+f\left(x_{i}\right)+\epsilon_{i} \\
& \forall x_{i} \in(c-h, c+h)
\end{aligned}
$$

where $Y_{i}$ is the outcome of interest for garbage collection area $i$ (the amounts of total MSW, refuse and recycling). The reported $\mathrm{RD}$ estimates correct for the bias and variance, as suggested in Cattaneo et al. (2019). The RD design assigns the treatment $\left(t_{i}\right)$ according to the week and year in which the garbage was collected, with data points after the policy change in August 1st, 
2015 being assigned to the treatment group. $x_{i}$ is the running variable (weeks in our setting), and $\mathrm{h}$ is the bandwidth around the cut-off point $c$. We determine the optimal bandwidth using the data-driven bandwidth selection procedure provided by Cattaneo et al. (2019). More specifically, we use the MSE-optimal and CER-optimal bandwidths by allowing both for common and different bandwidths in each side of the cut-off. We present the estimation results with different bandwidth selection procedures to ensure that they are not merely an artefact of the chosen bandwidth. We model the pre-trends and non-linearity in the running variable by the control function $f\left(x_{i}\right)$, which is a continuous n-order polynomial function of the running variable on each side of the cut-off $c$ (Cunningham (2020), Angrist and Pischke (2015)). Gelman and Imbens (2018) further recommend polynomials up to a quadratic to avoid the problem of over fitting. We use local linear regressions in our main specification (Imbens and Lemieux, 2008). We also test the robustness of our results with quadratic polynomial of the running variable. $e_{i}$ is a random, idiosyncratic error term. The standard errors are clustered by day which corresponds to garbage collection area in order to account for the specification error in the running variable (Lee and Card, 2008).

Other controls include garbage collection area dummies, which account for the historical differences in households' waste generation, and recycling behaviors across waste collection areas in global regressions. We also control for month dummies in the global regressions for the seasonality in waste generation over the year. Data-driven RD bandwidths are too small to allow for month fixed effects in the RD analysis. In RD design, controls are not generally considered necessary for identification but provide efficiency gains (Lee and Lemieux, 2010). We further estimate nonparametric estimations with the triangular kernel function, which further aids us to model the pre-trends and non-linearity, if any, in our analysis (Cunningham (2020). In addition, we complement our main specification by estimating models with Donut Hole Approach where we drop data points from the weeks around the cut-off.

The RD design enables us to identify the causal effects of the Clear Bag Policy on various outcomes as long as the changes in the households' waste generation and recycling behaviors around the discontinuity engendered by the Clear Bag Policy can be attributed to the policy change only, not to other independent factors. In our case, the timing of the policy change was not related to any changes in socioeconomic status or other potential contributors to the MSW stream ( Pemberton, 
2018), and it was universally implemented in all garbage collection areas. Given all this mounting evidence, it is plausible to expect that household waste management practices would have remained smooth over time in the absence of the policy change, lending credence to the continuity assumption. We provide further evidence to support the continuity assumption in the results section. It is also comforting that our data is daily and estimated bandwidths are relatively narrow spanning several months at the maximum, thereby significantly mitigating the possibility of a confounding policy change or other present confounders.

Nonetheless, we test whether there is any other discontinuity in our data through implementing placebo experiments with the pre- and post-policy data (Cattaneo et al. (2019); Cunningham (2020)). This placebo experiment with pre-policy data further allows us to tackle whether our results are merely an artefact of other potential pre-policy confounders. Following Imbens and Lemieux (2008), we estimate our RD specification using one side of the discontinuity and pretending there is an arbitrary discontinuity at the median value of the running variable, $c_{0^{\prime}}$, in this section. Further, we arbitrarily change the cut-off to the weeks preceding and following the policy change as additional falsification tests and find no evidence to suggest a discontinuity at these placebo experiments, bolstering our confidence to the RD specification.

In addition to a lack of any other pre- or post-policy discontinuity in our data, we note that despite the fact that the policy was strongly enforced by the municipality garbage collectors immediately at the launch of the program with wrongly disposed garbage rejected and the introduction of a new app to inform the households, minimal off-site dumping was observed. The manipulation or sorting around the cut-off is therefore not a concern in our setting. As described earlier in detail in the data section, we utilize the universe of the administrative data, on weekly garbage collection, thereby we can fully account for the potential biases which might have arisen from selection or sampling. Moreover, since we have the data for the garbage generation and collection of the entire population, a McCrary density test - an indirect test of whether individual has an indirect control over the assignment variable - is satisfied by design. Lastly, for the RD estimates to be valid, none of the control variables should display significant jumps around the cut-off (Calonico et al., 2019). This must be true for garbage collection fixed effects we use in our analysis since there was no change neither in the border of the garbage collection areas nor in the routes the garbage trucks 
followed during the period of our study.

\section{$5 \quad$ Effects of the Clear Bag Policy}

\subsection{Main Results}

We begin by estimating an ordinary least square (OLS) specification to investigate the association between the Clear Bag Policy and households' waste generation and recycling attitudes. OLS analysis simply compares the total MSW, refusal, recycling and organics before and after the policy change using whole available data and provides us with a benchmark to compare to our preferred estimates obtained from the RD specification. The unconditional OLS estimates, given in Table 3, Column 1, virtually mimics the raw changes presented in the last column of Table 1. Similar to the analysis presented in Table 1, we find that the Clear Bag Policy led to a significant increase in the amount of recycling, while decreasing both the amount of refuse and total MSW. In Columns (2) and (3) of Table 3, we present the conditional OLS estimates by controlling for the garbage area fixed effects and month fixed effects. In these specifications, garbage area fixed effects allow us to account for the time-invariant differences across garbage collection areas, whereas month fixed effects control for the seasonality in the data.

Both unconditional and conditional OLS estimates provide suggestive evidence indicating that the Clear Bag Policy not only encouraged households to recycle more ("reuse") but also to generate less total waste ("reduce"). More specifically, in our more rigorous specification presented in Column 3 , we find that the amount of refuse decreased by 12 tonnes per week, while recycling increased by more than 1 tonne per week, leading to around 10 tonnes decrease in overall MSW. Results in Table 3 further suggest that the estimated reduction in total MSW may be attributed to an overall reduction in waste generation ("reduce"). We also only observe an insignificant change in organics compared to other forms of waste during the time span of this study. As organics are collected in alternating weeks with refuse, if there were strong time trends driving the estimated OLS (as well as the $\mathrm{RD}$ results we describe later), we should observe the same time trends in organics as well. However, we fail to find any change in organics before and after the policy change in both OLS and 
RD specifications.

We now turn to the estimation results with RD design. As described in the estimation framework section, we exploit the discrete and abrupt change in the garbage collection practice instituted by the Clear Bag Policy to provide causal evidence on the effectiveness of the moral green nudge as an environmental policy instrument. As it is customary, we begin with the graphical illustration of the RD design where the total amount of total MSW (Figure 2a), refuse (Figure 2b), recycling (Figure 2c), organics (Figure 2d) were plotted against our running variable, week. Our cut-off week is week 83 , date at which the policy change took effect. These figures are generated using the data-driven optimal number of bins procedures suggested by Cattaneo et al. (2019). We also use polynomial of degree 1 for the running variable in these RD figures.

Figures 2a-2d visually demonstrate the significant impact the Clear Bag Policy had on households' waste generation, management and sorting. We continue to find similar evidence to the earlier OLS results on the effectiveness of this green nudge policy in promoting recycling and decreasing overall solid waste, as shown by the clear jump registered at the cut-off. As indicated earlier, organics remain virtually unaffected after the policy change (Figure 2d), confirming that the main mediators for the observed decline in solid waste are an increase in recycling (reuse) and an even larger decrease in refuse (reduce).

Next, we move to formally estimating our sharp RD specification. Results with garbage collection area controls are summarized in Table 4. Each cell in Table 4 comes from a separate regression with indicated variation of the main specification in bandwidth selection and polynomials. As discussed in detail in the identification strategy section, we present the robust RD estimates which are corrected for the bias and variance, as suggested in Cattaneo et al. (2019). We allow for both linear and quadratic polynomial in running variable with equal and different bandwidths in each side of the cut-off to model for the possibility of the pre-trends and non-linearity in our data. We further present the RD results with two data-driven bandwidth selection procedures summarized in Cattaneo et al. (2018), as well as results where we double the MSE-optimal and CER-optimal bandwidths to ensure that our results are not driven by the choice of the bandwidth, or polynomial degree of the running variable. We find that the $\mathrm{RD}$ estimates are robust to a different bandwidth selection procedures and polynomial choice for the running variable. 
Columns (1)-(5) of Table 4 show the RD estimates with MSE-optimal bandwidth selection, whereas Columns (6)-(10) describe the RD results with CER-optimal bandwidth with the associated bandwidths used in each regression. The outcome of interest in the first row is total MSW, which consists of the total of recycling, refuse and organic waste. The RD estimates also indicate that the Clear Bag Policy significantly reduced total MSW, and the estimation results are consistent across a battery of variations in specification with different data-driven bandwidths and polynomials of the running variable. More specifically, Column (1) demonstrates that total MSW was reduced by approximately 26 tonnes per week as a result of the Clear Bag Policy. Given that average total MSW was 97 tonnes per week before the green nudge was instituted, the RD estimate corresponds to a 27 percent reduction in MSW after the implementation of the policy.

As discussed earlier in the background section, by making garbage bags transparent (and thus inflicting a moral tax on individuals), one of the important goals for the Clear Bag Policy was to encourage more responsible "reduce, reuse, and recycle" behavior, thereby reducing the amount of refuse going to the landfill. Results to our RD estimation confirm the effectiveness of this moral green nudge in decreasing the amount of refuse (Table 4, Row 3). A local linear RD specification demonstrates that the Clear Bag Policy successfully reduced the amount of refuse by 17 tonnes per week overall (Table 4, Column 1). These results remain similar in magnitude and statistical significance with different bandwidth selection procedures and degrees of polynomial, and when we double the selected bandwidths, which provide supporting evidence on the robustness of our analysis.

Focusing next on recycling specifically, and further investigating to what extent households indeed altered their recycling behavior and attitudes after the policy change, we find evidence to indicate that recycling also increased after the implementation of the Clear Bag Policy. More specifically, with local linear RD specification, Table 4, Column (1) illustrates that the policy change led to an increase in recycling by more than 2 tonnes per week. This corresponds to a 14 percent increase in recycling after the Clear Bag Policy came into effect compared to the pre-program recycling. Finally, in some specifications, we also find a reduction in organics after the policy change; however, admittedly, the point estimates and statistical significance of the coefficients somewhat vary across specifications. Therefore, we are cautious in the interpretation of these 
results.

Evidence presented in Figures 2a - 2d and Table 4 clearly demonstrates that the Clear Bag Policy served as an effective policy instrument to gently nudge households towards more responsible waste management practices, as intended. Taken together, our results show that residents of Halifax began to expend more effort in sorting their MSW as a result of this relatively cost-effective environmental policy. However, the more careful sorting explains only some of the change in our results. When we focus on total MSW, we further find that the Clear Bag Policy had an impact on residents' behavior regarding waste overall (reduce). Both changes in households' behavior in waste management as well as waste generation likely have contributed to the estimated reduction in MSW.

\subsection{Robustness Tests and Validity Checks}

In this subsection, we provide additional evidence on the robustness of our main results and formally test their validity. In this pursuit, we performed a battery of validity checks as suggested in Cattaneo et al. (2019) to ensure that our data exhibits no other jumps before and after the policy, and that our findings are not sensitive to observations near the cut-off. Moreover, as explained in the previous section, the RD estimates remain virtually unchanged with data-driven MSE-optimal and CER-optimal bandwidth selection procedures, as well as when we double the MSE-optimal and CER-optimal bandwidths. Similarly, our results are robust to varying degrees of polynomial of the running variable, as shown in Table 4. We conclude therefore that our results are not sensitive to the selection of the bandwidth procedures or a degree of polynomials of the running variable.

Another potential concern for the interpretation of the RD results is the potential manipulation and sorting around the cut-off. As mentioned in the identification section, we have an administrative data on the entire population on waste collection as the municipality is the sole garbage collector in our setting. Moreover, local government run several public campaigns to promote the new policy and inform the residents on the upcoming changes in waste management under the new garbage collection rules. In addition, immediately after the launch of the program, the policy was strongly enforced by the municipality garbage collectors, with wrongly disposed garbage rejected and a minimal off-site dumping. Therefore, sorting or manipulation which could be a concern for the interpretation of the $\mathrm{RD}$ estimates are unlikely to be present in this setting. 
We provide further evidence suggesting that our results are not sensitive to inclusion of the observations near the cut-off by estimating the RD specification with Donut Radius Approach. This approach effectively drops the cut-off week as well as weeks preceding and following the policy change. As is summarized in Table 5, we compare three different radii for our Donut Hole approach: Radius 1 (dropping week 83, when the Clear Bag Policy was implemented) (Column 2), Radius 3 (dropping weeks 82-84) (Column 3), and Radius 5 (dropping weeks 81-85) (Column 4). We use the MSE-optimal bandwidth selection procedures and local linear regressions with equal bandwidth on each side of the cut-off for all of these analyses presented in Table 5. Overall, the results remain similar in magnitude and statistical significance as those from our baseline RD estimator (Column 1). With the Donut Hole Approach, we continue to find that the Clear Bag Policy successfully led to an increase in recycling, a decrease in refuse, and, perhaps equally importantly, an overall decrease in the total MSW generated.

We further perform several placebo experiments with different cut-offs before and after the policy as well as arbitrarily assigning the cut-off one week before and after the policy change to ensure that our data pertains no other jumps besides the cut-off. In the first set of results summarized in Table 6, we exclusively focus on the observations from the pre-policy period and estimate the local linear RD specification both with MSE-optimal and CER-optimal bandwidth selection procedures by pretending there is an arbitrary discontinuity at the median value of the running variable, $c_{0^{\prime}}$, in this section. We present the robust RD estimates with MSE-optimal bandwidth selection in Column (1) and CER-optimal bandwidth selection in Column (2). In the second sets of results we use the observations after the Clear Bag Policy and estimate the robust RD specification with the median value of the running variable in post-policy section, as summarized in Columns (4) and (5). As additional check, in Column (3), we also change the cut-off a week before the policy change. Finally, we move the cut-off by a week after the policy change in Column (6) to test the sensitivity of our results to the cut-off. All point estimates in these alternative cut-offs are statistically insignificant bolstering our confidence that the estimated effects of the Clear Bag Policy are indeed due to the change in the garbage collection rules rather than other confounding factors, jumps or non-linearity in the data. 


\subsection{Heterogeneity in the Effects of Clear Bag Policy}

We now turn to estimating the heterogeneous effects of the Clear Bag Policy across garbage collection areas. As mentioned earlier in the descriptive statistics section, it is of interest to quantify the association between households' socioeconomic indicators and their response to the green nudge policies in waste management. However, admittedly, our estimations lose some precision when we exclusively focus on a single garbage collection area; thereby the analysis we discuss in this subsection provide a suggestive evidence on the heterogeneous effects of the Clear Bag Policy.

We start by presenting the RD plots on total MSW for each garbage collection area in Figures 3a-3e. Similar to the descriptive statistics summarized in Appendix Table 1A, these RD plots demonstrate that the Clear Bag Policy led to a sizable reduction in total MSW in all areas with the exception of South End, which is the most affluent area in HRM. To further complement our analysis, we next present the garbage area specific RD plots for refuse and recycling in Figures 4a-4e and Figures 5a-5e, respectively. In both sets of figures, we find that the desired goals of the policy have been achieved in terms of refuse reduction, while the magnitude of the effects vary across areas. All areas exhibited a sharp increase in recycling at the cut-off point, most drastically in the affluent South End and West End.

The results presented in the RD graphs are confirmed by the garbage area specific RD estimations in Appendix Table 2. All areas experienced a significant reduction in refuse, where the magnitude of the robust RD estimates in Clayton Park and Spryfield - areas with overall lower income levels and educational attainment - is almost twice the size as for other areas. These areas also exhibit a significant reduction in overall solid waste, potentially suggesting a more radical change in the consumption behavior and attitudes among the households residing these areas after the implementation of Clear Bag Policy. We also note that these areas had more refuse and MSW before the policy change, indicating there was more room for improvement. Finally, we find in Appendix Table 2 that recycling significantly increased in the West End and North End after the policy change, while the estimated point estimates are not statistically significant at the conventional level for other areas. According to the census data, these areas have the lowest income per capita, and employment rates; thus, our results provide suggestive evidence that the Clear Bag Policy has been successful in promoting more responsible recycling among households with lower 
socioeconomic status.

\section{Discussion}

The ultimate goal of the Clear Bag policy was to gently nudge households to revise their consumption habits and reduce their overall waste production, by paying more attention to the impact that their purchasing choices had on the waste stream, by choosing to bring their own bags to the grocery store, for example, or choosing to buy items with less packaging overall. Given that we find both amount of total MSW and refuse have been reduced as a result of the Clear Bag Policy and as we discuss in more detail later there was minimal off-site illegal dumping, our results suggest that this green nudge policy indeed achieved the elusive goal of reducing waste production as intended.

The new policy also seems to have promoted better sorting among households and local waste pickers alike. The greater visibility of the contents of the garbage under the new policy allows local waste pickers to collect the redeemable items more easily before collection day and return them directly to redemption centers to collect their deposits, while some bottles and cans were used to be discarded in black garbage bags before the policy. The 2016 Annual Report of Divert Nova Scotia indeed documents a significant increase in container redemption (Divert Nova Scotia, 2016); thereby supporting the increasing diversion from the landfills and consequently a reduction in the amount of refuse we find in our analysis.

In addition to the redeemable items which now can be easily spotted within the clean bags, clothing and other items which could potentially be diverted from landfills also became visible to garbage collectors, neighbors and local waste pickers. This alone may have merely motivated residents to donate the clothing and small appliances to charity organizations which have donation boxes across the city. An increase in charity donations especially in clothing would divert these items from the landfill as intended and lead to more recycling and reuse, further supporting the efficacy of the green nudge. In fact, Halifax has a large secondhand market with several Value Village (similar to Goodwill stores in the U.S.) and Salvation Army stores located across the

city and high volume of secondhand transaction. In addition, with the new clear bags, garbage pickers can see the clothing inside the bags or households generally leave the clothing and small 
appliances on the curb for garbage pickers, both of which promote "reuse" and effectively divert these items from landfill. In efforts to provide more evidence on the increasing donations to Value Village, we have interviewed the manager of the Halifax Branch. He reported that the amount of donations substantially increased after the implementation of the Clear Bag Policy, thereby providing supporting evidence on the effectiveness of the policy in diverting clothing and small appliances from the landfill. 14

Another contributing factor to the reduction in refuse and total MSW has been the increase in commercial garbage use. With the new policy, residents increasingly started to take additional garbage directly to the landfill and pay the commercial fee. Similar to households, small businesses that used to hide their debris in black bags and have them collected, for free, residentially (e.g. renovations done in residences) are now more likely to dispose properly and for a fee (commercially) for that service. To that effect, the HRM Solid Waste Department indeed has recorded an overall increase in commercial garbage being collected after the implementation of the clear bag policy (Pemberton, 2018), which suggests that the part of the change in MSW can be attributed to the increasing rates of commercial garbage use.

Alternatively, the clear bag policy could have prompted households to dump their garbage illegally in commercial bins or off-site areas or take it to their workplace. Concerned by this eventuality, the HRM Solid Waste Resource Department monitored the potential off-site locations for illegal dumping. They report encountering no evidence to suggest an escalation of off-site illegal dumping after the launch of the Clear Bag Policy (Pemberton, 2018). Similarly, since the Clear Bag Policy has been in place for several years now, it is unsustainable to take the household garbage to work for such extended periods. Thus, it is unlikely that our results are driven by either illegal dumping or relocation of the garbage from homes to workplaces.

In addition to the immediate response to the policy we discussed above, it is of policy interest to assess the longer-term effects of such policies in maintaining the initial improvements in more responsible household waste sorting and reducing efforts. Indeed, much discussed policy concern raised by the opponents of nudges is whether nudges facilitate persistence behavioral changes as intended or behavioral changes are short lived, where people return to their old habits after the

\footnotetext{
${ }^{14}$ The Clear Bag Policy did not bring any change to the collection of large household items such as furniture for example. These are picked up at the curb on garbage day free of charge.
} 
initial phase of the policy or nudge when promotions and enforcement fade out. As we have data covering several years after the implementation of the policy change, we are able to observe whether initial changes in attitudes we describe above have "softened" after some time. Our analysis shows a slight increase in refuse, and a decline in recycling after the first year of the program. However, we find that the total MSW does not seem to have exhibited any further changes after the initial drop associated with the policy. Thus, our analysis provides suggestive evidence that green nudges could indeed facilitate the desired persistent behavior changes in waste management as well as waste generation not only in the immediate aftermath of the policy change but also in the medium run. Our analysis further demonstrates that policy concerns on the persistence and permanence of the green nudges and nudges in general in altering households' behavior is not warranted in our context. These results thus provide further supportive evidence for utilizing green nudges in the environmental policy design.

Finally, we elaborate further in this section whether the Clear Bag Policy we study in our paper indeed can be classified as a moral green nudge. Thaler and Sunstein (2008) define a green nudge as a "change in any aspect of the choice architecture that is intended to alter people's behavior in a predictable way and result in a reduction of a negative external effect [in italic in the text] without forbidding any option or significantly changing the economic incentives" (cited in Hausman and Welsh (2010) and Carlsson et al. (2019)). Further, Carlsson et al. (2019) explain how "[a] green nudge does not aim to correct a "mistake" in decision-making but, instead, uses people's biases and moral utility to nudge them away from creating negative externality" (Carlsson et al (2019), Schubert (2017) also, p.331). One type of effective green nudge is for example making the green option the default option. Even though, the above definition is generally used in the literature, the idea of a minimal cost being imposed on individuals that is associated with the concept of nudge is sometimes/often blurred. Studies by Moseley and Stoker (2013) have tried to address this issue by suggesting different categories of nudges, namely three, that governments may use to "engage in Nudge practices" (p4 in the text): framing, persuasion, and norm-creation, and where the cost imposed on individuals vary (framing being the least costly one).

The Clear Bag Policy can be classified as a moral green nudge since its design incorporated the various aspects of nudges we described earlier. Under the Clear Bag policy, residents still 
had options. For instance, in addition to up to 5 clear bags every other week, households were still allowed to use one additional black bag and this option has been utilized as well. Further, households can also opt to bring their refuse to the landfill facility directly. Finally, we note that one reason the MSW policies in general (and in this case as well) cannot be too coercive (or impose too high of a cost to individuals) stems from the fact that people would then tend to discard their refuse in nearby woods and rivers (or at their neighbors' steps). There is no evidence suggesting such a response occurred after the clear bag policy was implemented; thereby demonstrating the efficacy of its design and implementation.

\section{Conclusion}

Reducing the impact our consumption pattern has on the environment has become an imperative for today's societies on a global scale. Given the astounding amount of solid wastes and ever-growing supply of plastics which we generate, a quest for an effective and lower cost solid waste management and solid waste reduction policies have been at the center of the environmental policy debate. For such environmental policies to be successful in encouraging "reduce, reuse, and recycling" actions, policymakers are experimenting with nudges. This paper provides one of the first causal evidence on the effectiveness of a non-price incentive environment policy, or "green nudge", as a waste management policy instrument. We quantify the potential impacts of such a green nudge on recycling, sorting and MSW generation by exploring the Clear Bag Policy instituted in a mid-size city in Atlantic Canada on August 1, 2015. By mandating households to switch to clear, transparent garbage bags from black garbage bags, the Clear Bag Policy aimed to gently nudge households towards more responsible sorting, recycling and ultimately reduction in waste generation.

Given the novel setting of this policy change and the availability of the daily administrative data on residential curbside solid waste from five different garbage collection areas in the city, we are able to analyze the impact of the policy using a Regression Discontinuity (RD) design. Our findings demonstrate that the impact of the Clear Bag Policy has been economically and statistically significant and effective in promoting recycling, selective sorting, and reducing refuse and overall MSW. The policy led to a substitution between recycling and reducing, wherein the 
overall reduction in MSW is smaller than the decrease in the amount of refuse. An increasing diversion of the redeemable items, clothing and small appliances from landfill and the growing use of the commercial garbage for fee are potential mediators explaining our findings. Finally, we further investigated in our paper how this green nudge affected differently households with varying socioeconomic backgrounds. Using ArcGIS to map out the 2011 Census data with our administrative data on MSW, we find suggestive evidence on potential heterogeneity of effects associated with the policy across garbage collection areas with different average household income and educational attainment. Our results demonstrate that areas with lower average income and educational attainment exhibit more significant improvements in their waste management and generation, thereby suggesting that green nudges could also be effective in alleviating differences in waste management across socioeconomic status.

Even though green nudges have been increasingly implemented as an alternative environment policy tool to "gently push individuals in the right direction", there is still an ongoing debate on their effectiveness in producing the desired behavioral responses and whether these changes in behavior indeed are persistent and permanent. Our analysis contributes to this discussion by demonstrating that non-price environmental policies, such as the Clear Bag Policy we studied in this paper, may indeed be an effective way to facilitate more responsible sorting and waste generation, and a lowcost alternative to policymakers, compared to the traditional waste management policies such as imposing fees or paying higher taxes. The Clear Bag Policy has produced the desired impacts on household behavior via better and higher recycling and overall solid waste reduction without imposing a higher tax on household income or charging fees for disposal, or a change in the number of refuse bags allowed biweekly. Our results further reveal that the positive environmental benefits generated by green nudges are not limited to the period immediately after the policy change, but also persist in the longer time horizons, even though the longer-term effects do appear to become smaller. Thus, we caution policy makers on this latter observation, and encourage both a continual promotion and enforcement of the policy to achieve the desired behavioral changes, along with additional measures aiming at preventing waste production, enforcing stricter rules on packaging, and banning the use of single use plastics. 


\section{References}

Allcott, Hunt, and Judd B Kessler (2019) The Welfare Effects of Nudges: A case Study of Energy Use social Comparisons. American Economic Journal: Applied Economics, 11(1): 236-276.

Allcott, Hunt, and Todd Rogers (2014) The Short-Run and Long-Run Effects of Behavioral Interventions: Experimental Evidence from Energy Conservation. American Economic Review, 104(10): 3003-3037.

Alpizar, Francisco, and Elisabeth Gsottbauer (2015) Reputation and Household Recycling Practices: Field Experiments in Costa Rica. Ecological Economics, 120: 366-375.

Angrist, Joshua and Joern-Steffen Pischke. 2015. Mastering Metrics: The Path from Cause to Effect. Princeton University Press.

Ariely, Tom, George Loewenstein, and Drazen Prelec (2006) Tom Sawyer and the Construction of Value. Journal of Economic Behavior \& Organization, 60: 1-10.

Babooram, Avani, and Jennie Wang (2013) Recycling in Canada. Statistics Canada. Accessed online at http://www.statcan.gc.ca/pub/16-002-x/2007001/article/10174-eng.htm. March $1,2016$.

Barr, Stewart, Andrew W. Gilg, and Nicholas J. Ford (2001) A Conceptual Framework for Understanding and Analyzing Attitudes towards Household-waste Management. Environment and Planning A, 33: 2025-2048.

Bernstad, Anna, Jes la Cour Jansen, and Henrik Aspefren (2012) Local Strategies for Efficient Management of Solid Household Waste -The Full-scale Augustenborg Experiment. Waste Management \& Research, 30(2): 200-212.

Brent, Daniel A., Corey Lott, Michael Taylor, Joseph Cook, Kim Rollins, and Shawn Stoddard (2016) Are Behavioral Nudges Moral Taxes? Evidence from a Field Experiment on Water Conservation. Working Paper. 
Calonico, Sebastian, Matias D. Cattaneo, Max H. Farrell, and Rocio Titiunik (2019) Regression Discontinuity Designs Using Covariates The Review of Economics and Statistics, 101(3):442-451.

Carlsson Frederik, Christina Gravert, Olof Johansson-Stenman, and Verena Kurz (2018) Presentation at the World Congress of Environmental and Resources Economists (WCERE), Gothenburg, Sweden, June 2018.

Carlsson Fredrik and Olof Johansson-Stenman (April 2019) Optimal Prosocial Nudging. Working Paper in economics No $75 \%$.

Carlsson, Frederik, Christina Gravert, Olof Johansson-Stenman, and Verena Kurz (2019) Nudging as an Environmental Policy Instrument. Working Papers in Economics 756, University of Gothenburg, Department of Economics.

Cattaneo, M., N. Idrobo, and R. Titiunik (2019) A Practical Introduction to Regression Discontinuity Designs: Foundations Cambridge Elements: Quantitative and Computational Methods for Social Science. Cambridge University Press.

CBC News (2015) "Trash talk: your questions answered about clear bags," http:///www.cbc.ca/ news/canada/nova-scotia/trash-talk-your-questions-answered-about-clear-bags-1. 3165472. July 23, 2015.

Cecere, Grazia, Susanna Mancinelli, and Massimiliano Mazzanti (2014) Waste Prevention and Social Preferences: The Role of Intrinsic and Extrinsic Motivations. Ecological Economics, 107:163176.

Cox, Jayne, Sara Giorgi, Veronica Sharp, Kit Strange, David C. Wilson, and Nick Blakey (2010) Household Waste Prevention - A Review of the Evidence. Waste Management $\&$ Research, 28: 193-219.

Cunningham, Scott. (2020) Causal Inference: The Mixedtape Yale University Press.

D’Amato, Alessio, Susanna Mancinelli, and Mariangela Zoli (2016) Complementarity vs Substitutability in Waste Management Behaviors. Ecological Economics, 123: 84-94. 
Dahlen, Lisa, and Anders Lagerkvist (2010) Evaluation of Recycling Programmes in Household Waste Collection systems. Waste Management $\&$ Research, 28: 577-586.

Divert Nova Scotia (2016) Annual Report 2016. Accessed online at http://divertns.ca/assets/ files/DivertNS_AnnualReport2016.PDF. February 20, 2018.

Ferraro, Paul J., and Michael K price (2013) Using Nonpecuniary Strategies to Influence Behavior: Evidence from a Large-scale Field Experiment, Review of Economics and Statistics, 95(1): 64-73.

Gelman, Andrew, and Guido Imbens (2018) Why High-Order Polynomials Should Not Be Used in Regression Discontinuity Designs. Journal of Business $\&$ Economic Statistics, Vol. 0, No. 0.

Halifax Regional Municipality (HRM) (2016). Introduction to Halifax: Proposed Operating Budget 2015-2016. Accessed online March 1, 2017.

Hansen, Pelle Guldborg (2016) The Definition of Nudge and Libertarian Paternalism: Does the Hand Fit the Glove? European Journal of Risk and Regulation, 1: 155-174.

Hausman Daniel M., and Brynn Welch (2010) Debate: To Nudge or Not to Nudge. The Journal of Political Philosophy, 18(1): 123-136.

Hoomweg, Daniel, and Perinaz Bhada-Tata (2012) What a Waste: A Global Review of Solid Waste Management. World Bank Working Paper 68135.

Imbens, Guido, and Thomas Lemieux (2008) Regression Discontinuity Designs: A Guide to Practice. Journal of Econometrics, 142(2): 615-635.

Kahneman, Daniel (2011) Thinking Fast and Slow. Farrar, Straus and Giroux, NY.

Kinnaman, Thomas, Takayoshi Shinkuma, and Masashi Yamamoto (2014) The Socially Optimal Recycling Rate: Evidence from Japan. Journal of Environmental Economics and Management, 68: $54-70$.

Kirakozian, Ankinee (2016) The Determinants of Household Recycling: Social Influence, Public Policies and Environmental Preferences. Applied Economics, 48(16): 1481-1503. 
Lee, David S., and David Card (2008) Regression Discontinuity Inference with Specification Error. Journal of Econometrics, 142(2): 655-674.

Lee, David S., and Thomas Lemieux (2010) Regression Discontinuity Designs in Economics, Journal of Economic Literature, 48(2): 281-355.

Meyer, Andrew (2015) Does Education Increase Pro-environmental Behavior? Evidence from Europe. Ecological Economics, 116: 108-121.

Moseley Alice, and Gerry Stoker (2013) Nudging Citizens? Prospects and Pitfalls Confronting a New Heuristic. Resources, Conservation and Recycling, 79: 4-10.

Nolan, Jessica M., P. Wesley Schultz, Robert B. Cialdini, Noah J. Goldtsein, and Vladas Griskevicius (2008) Normative Social Influence is Underdetected. Personality and Social Psychology Bulletin, 34: 913-923.

Nova Scotia Environment (1995) Final Report on Nova Scotia's 1995 Solid Waste Resource Management Strategy. Government of Nova Scotia. Accessed online at http://www.novascotia.ca/ nse/waste/docs/SolidWasteStrategyFinalReport1995.pdf. March 2, 2016.

Nova Scotia Environment (2014) Environmental Goals and Sustainable prosperity Act: Progress Report 2012-2014. Accessed online at https://novascotia.ca/nse/egspa/docs/ EGSPA-2012-2104-Progress-Report.pdf. March 2, 2017.

Pemberton, Clayton (2018) Email Correspondence. HRM Solid Waste Resources, February 16, 2018.

Schubert, Christian (2017) Green Nudges: Do They Work? Are They Ethical? Ecological Economics, 132: 329-342.

Statistics Canada (2011) 2011 Census Profile of Population, National Household Survey (NHS). Accessed online http://www12.statcan.gc.ca/census-recensement/2011/dp-pd/prof/index. cfm?Lang=E, March 2, 2016) 
Statistics Canada (2016) Data products 2016 Census. Accessed online at http://www12.statcan. gc.ca/census-recensement/2016/dp-pd/index-eng.cfm, March 1, 2017.

Statistics Canada (2017) Median total income, by family type, by census metropolitan area (All census families) CANSIM, table 111-009. Accessed online at http://www.statcan.gc.ca/ tables-tableaux/sum-som/101/cst01/famil107a-eng.htm. January 25, 2018.

Statistics Canada (2018) Labour force characteristics, seasonally adjusted, by census metropolitan area (3 month moving average). Accessed online athttp://www.statcan.gc.ca/ tables-tableaux/sum-som/101/cst01/lfss03a-eng.htm. January 16, 2018.

Thaler, Richard H., and Cass R. Sunstein (2008) Nudge: Improving Decisions about Health, Wealth, and Happiness. Yale University Press.

Zacho, Kristina O., and Mette A. Mosgaard (2016) Understanding the role of waste prevention in local waste management: A literature review. Waste Management $\mathscr{G}$ Research, 34(1): 980-994. 
Figure 1: Dissemination areas of HRM and waste collection areas

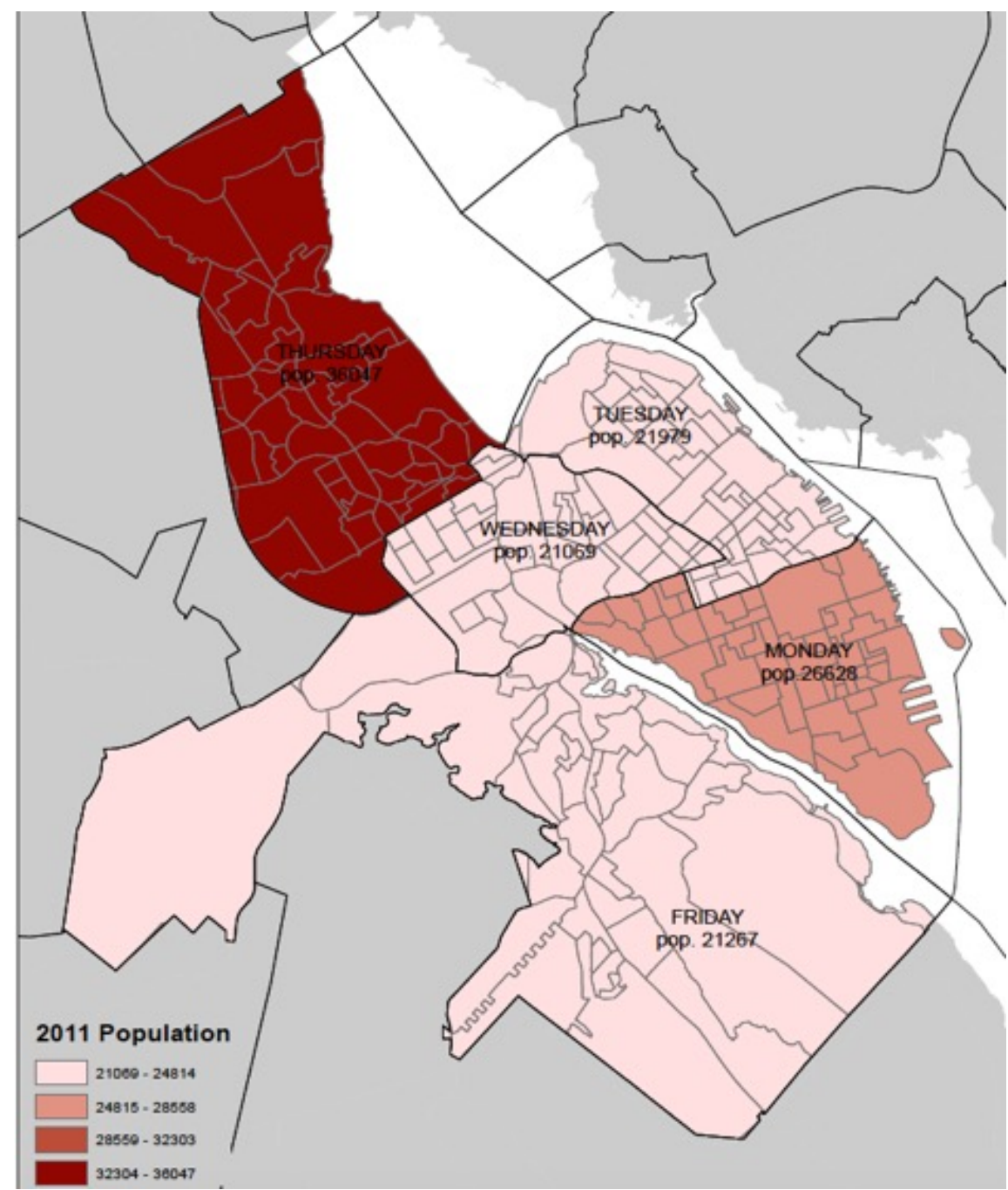

Source: Data are taken from the 2011 Canadian Census 
Figure 2: RD Plots

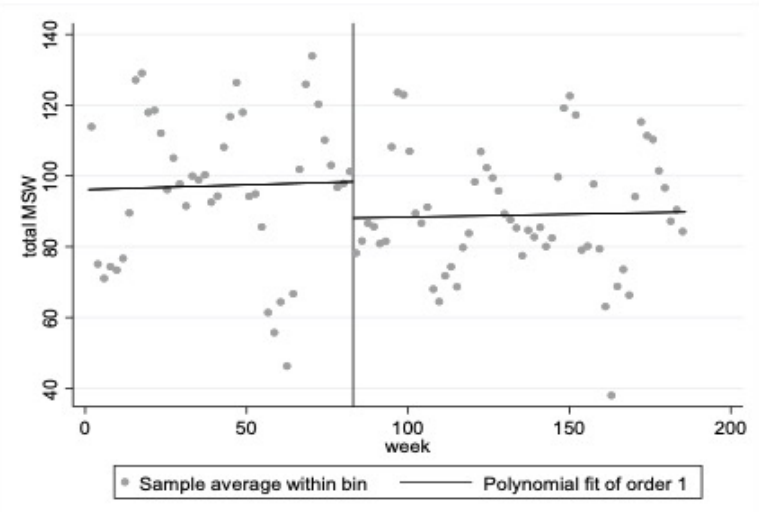

(a) Total MSW

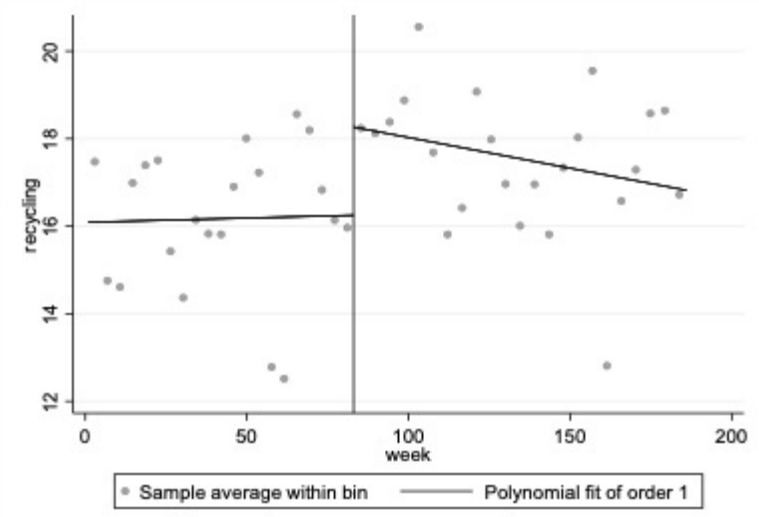

(c) Recycling

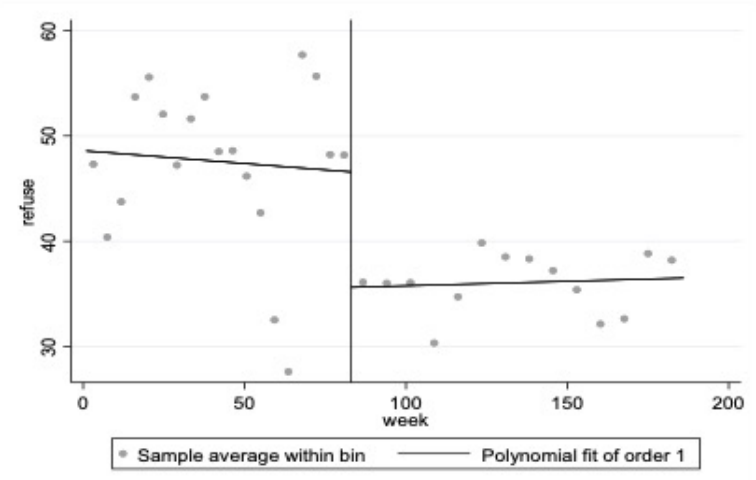

(b) Refuse

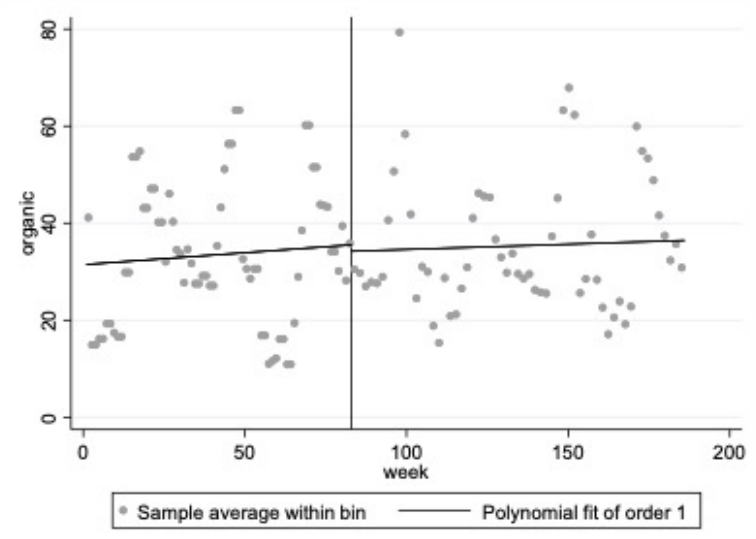

(d) Organics 
Figure 3: RD Plots for MSW by Area

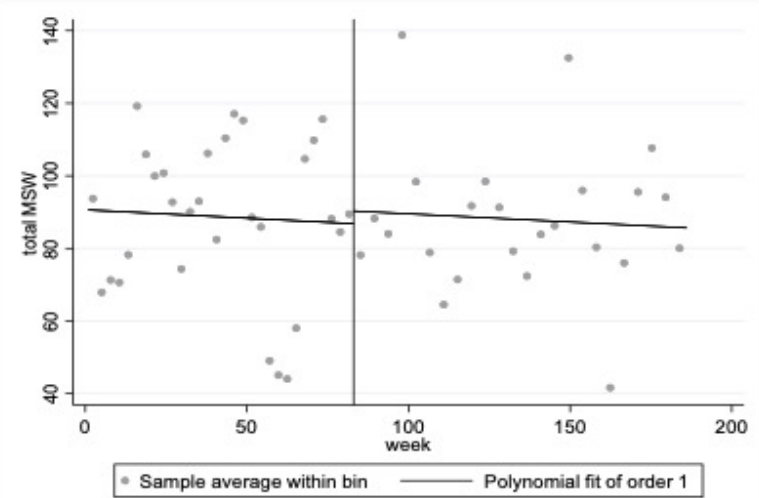

(a) South End

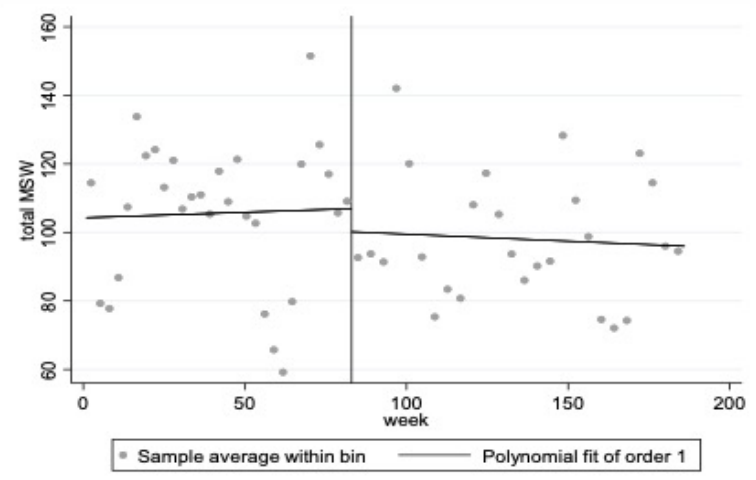

(c) West End

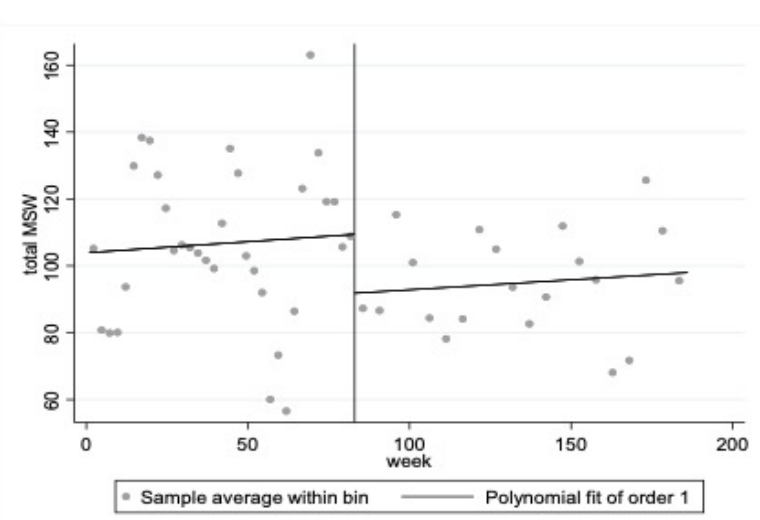

(e) Spryfield

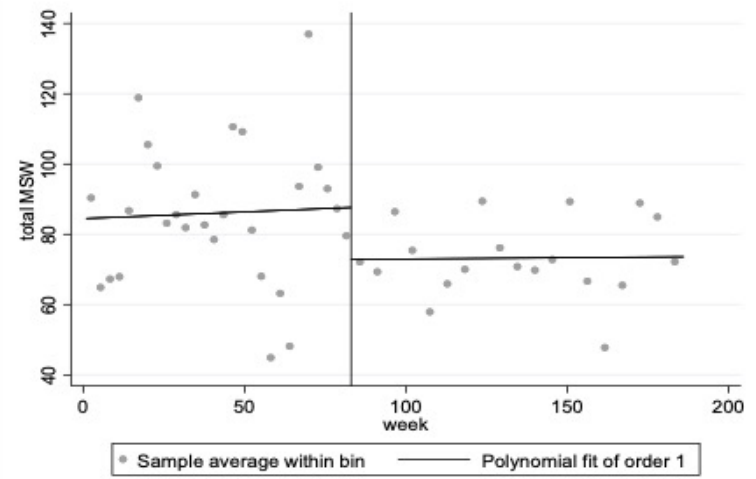

(b) North End

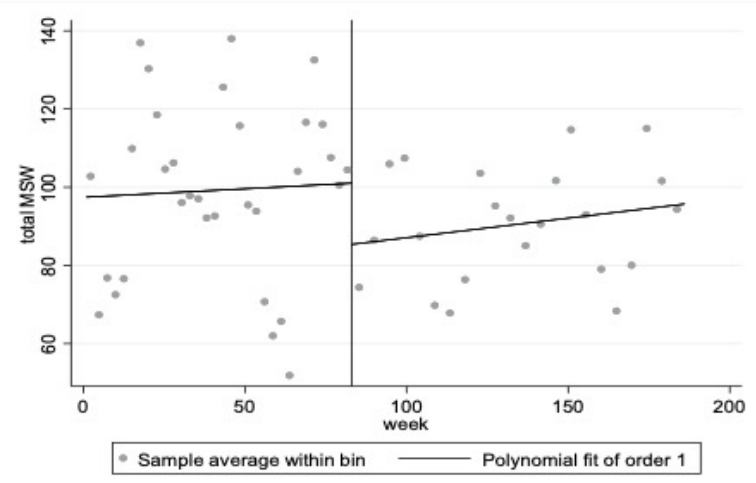

(d) Clayton Park 
Figure 4: RD Plot for Refuse by Garbage Collection Areas

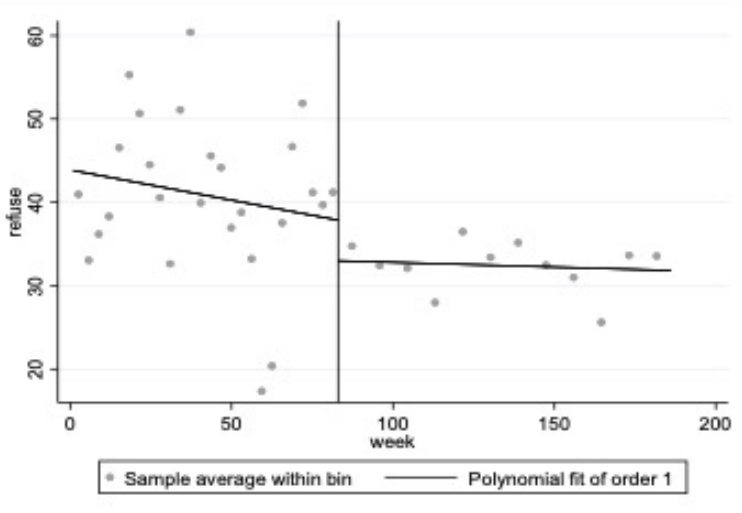

(a) South End

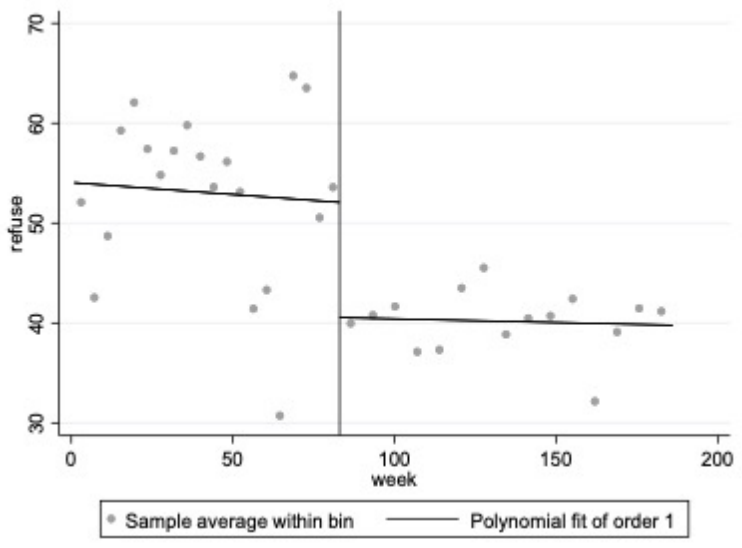

(c) West End

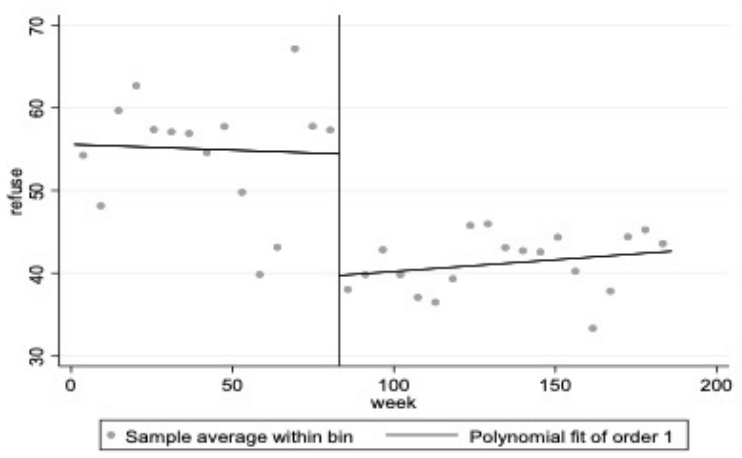

(e) Spryfield

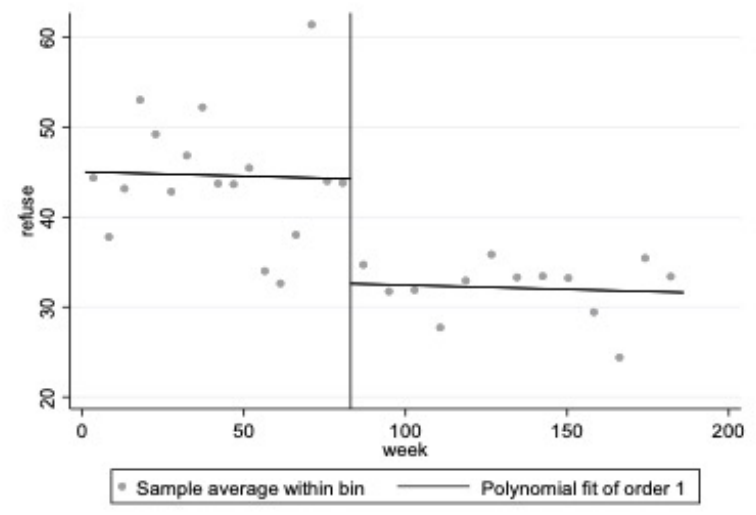

(b) North End

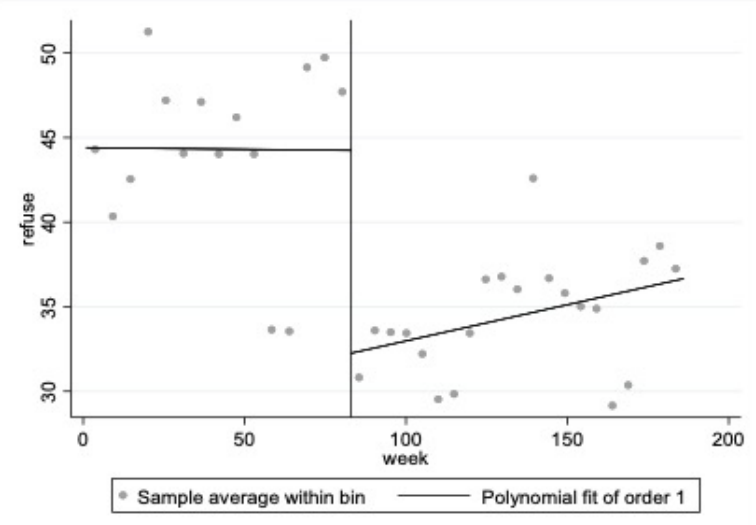

(d) Clayton Park 
Figure 5: RD plots for Recycling by Garbage Collection Area

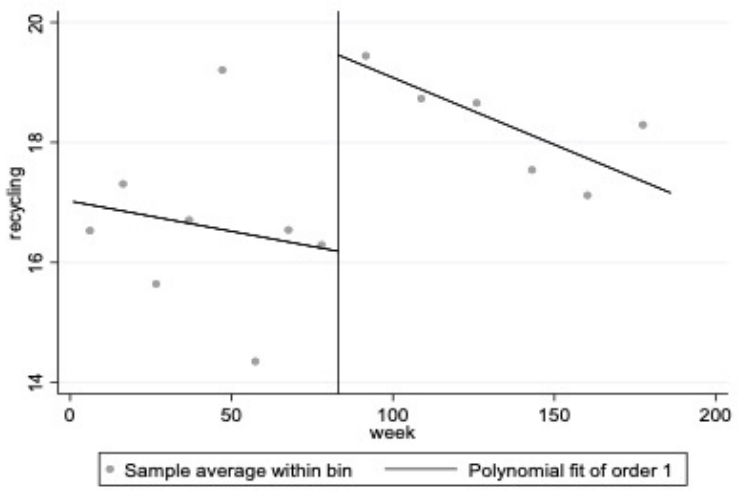

(a) South End

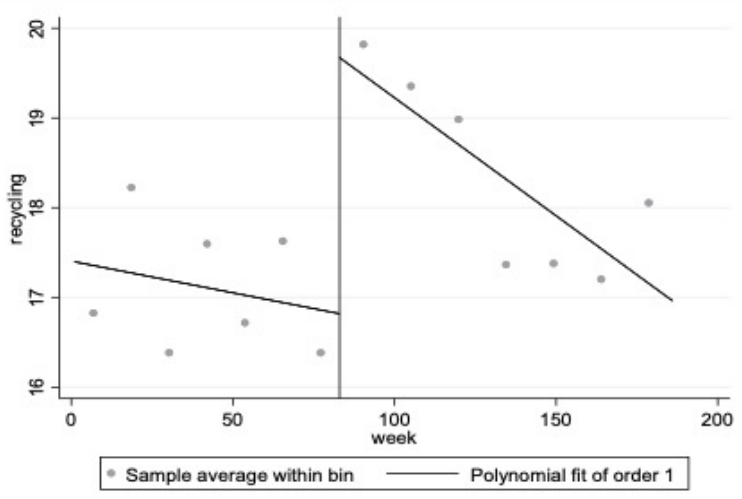

(c) West End

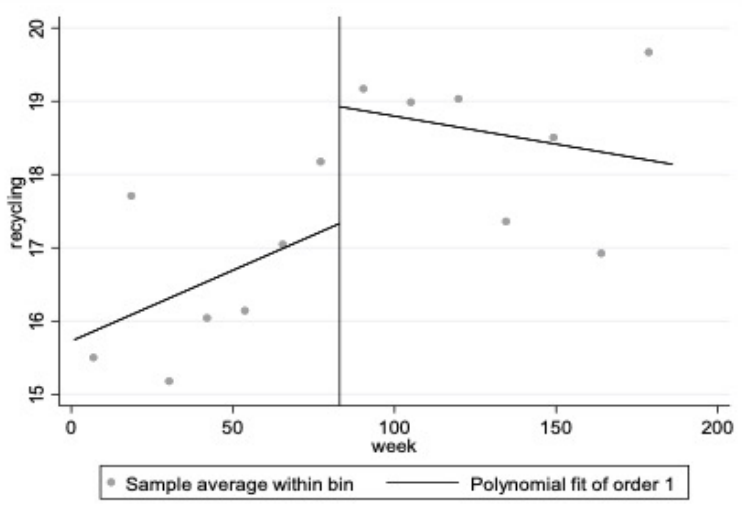

(e) Spryfield

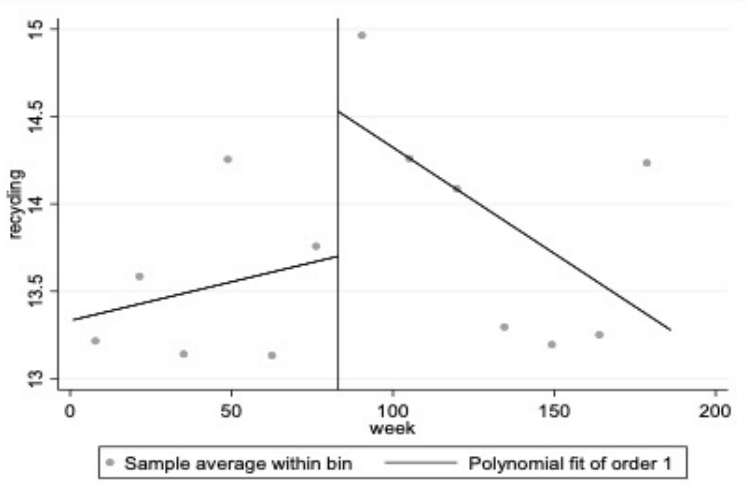

(b) North End

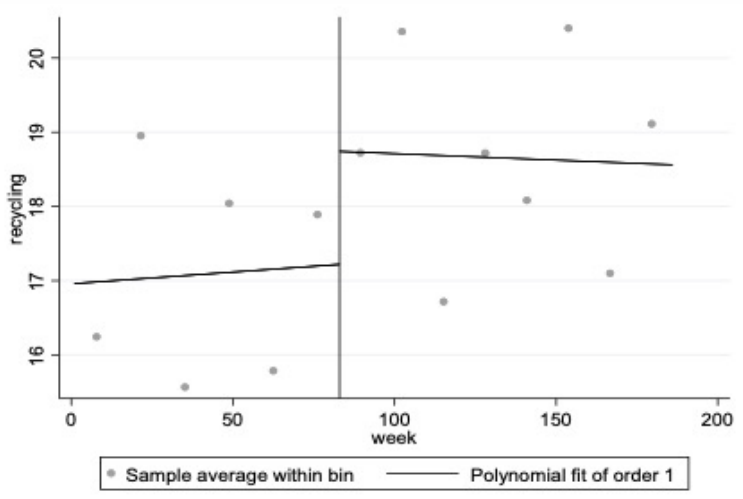

(d) Clayton Park 